\title{
bPAG PROFILES IN RECIPIENT HEIFERS AFTER TRANSFER OF IVF AND NUCLEAR TRANSFER EMBRYOS
}

F.J. Ectors, ${ }^{1}$ M. Schmidt, ${ }^{2}$ L.C. Smith, ${ }^{3}$ J. Sulon, ${ }^{1}$ A. Delval,

B. Remy, 1 B. Avery, ${ }^{2}$ and J-F. Beckers ${ }^{1}$

1IRSIA Research Unit, Sart Tilman, Belgium

2Department of Clinical Studies, Reproduction.

Copenhagen, Denmark

${ }_{3}^{3}$ CRRA, Saint-Hyacinthe, Québec

Bovine pregnancy associated glycoproteins (bPAG) are secreted by trophoblast continuously thoughout gestation with concentrations increasing from implantation to the end of pregnancy (Zoli et al., Biol. Reprod., 46, 83-92, 1992). Following the bPAG levels released after transfer of IVF and nuclear transfer (NT) embryos during pregnancy may be useful for prediction of fetal well-being and help to detect early placental abnormalities, embryonic mortality or abortion. The aim of this experiment was to determine bPAG levels in heifers bearing embryos and fetuses after non surgical transfer of two embryos produced in vitro (IVF) or by nuclear transfer.

IVF and transfer of these embryos were carried out in Denmark, NT and transfer of the cloned embryos were done in Belgium. Blood samples were collected weekly or twice monthly during pregnancy. A radioimmunoassay for bPAG was developed in the Belgian laboratory according to the method described by Zoli et al.

In the IVF group, no pregnancy loss occurred after day 42 and the calving rate was $64 \%$. In the cloned group, 2 abortions occurred in mid pregnancy (days $\approx 80$ and $\approx 180$ ) and the calving ratc was $21 \%$. Data are shown in the table.

Table: concentrations ( $\mathrm{ng} / \mathrm{ml}$; means $\pm \mathrm{SEM})$ of $\mathrm{bPAG}$ in single and twin pregnancies:

\begin{tabular}{|c|c|c|c|c|}
\hline \multirow[b]{2}{*}{$\begin{array}{l}\text { Weeks } \\
\text { after ET }\end{array}$} & \multicolumn{2}{|c|}{ IVF embryos giving } & \multicolumn{2}{|c|}{ NT embryos giving } \\
\hline & $\begin{array}{c}\text { twins } \\
n=7\end{array}$ & $\underset{n=7}{\text { singles }}$ & $\begin{array}{l}\text { twin } \\
n=1\end{array}$ & $\begin{array}{c}\text { singles } \\
\mathrm{n}=7\end{array}$ \\
\hline 3 & $3 \pm 0.3$ & $2 \pm 0.2$ & $T$ & 7 \\
\hline 5 & $7 \pm 0.8$ & $3 \pm 0.5$ & 2 & $2 \pm 0.3$ \\
\hline 7 & $9 \pm 0.9$ & $5 \pm 1.2$ & 1 & 1 \\
\hline 8 & $10 \pm 0.9$ & $7 \pm 1.5$ & 7 & $5 \pm 0.3$ \\
\hline 12 & $28 \pm 2.2$ & $21 \pm 2.6$ & 18 & $10 \pm 2.9$ \\
\hline 26 & $128 \pm 21$ & $73 \pm 16$ & 456 & $79 \pm 12$ \\
\hline 29 & $157 \pm 21$ & $108 \pm 28$ & 730 & $119 \pm 29$ \\
\hline 32 & $209 \pm 38$ & $148 \pm 33$ & 630 & $204 \pm 51$ \\
\hline 35 & $223 \pm 25$ & $137 \pm 28$ & 360 & $252 \pm 60$ \\
\hline 36 & $242 \pm 45$ & $168 \pm 40$ & 348 & $248 \pm 59$ \\
\hline $\begin{array}{l}\text { Peripdarlal } \\
\text { week }\end{array}$ & $2264 \pm 380$ & $1602 \pm 559$ & 12350 & $5022 \pm 1789$ \\
\hline
\end{tabular}

Similar bPAG levels were observed in the IVF and NT groups, except around parturition where higher concentrations were found in the cloned group. Twin pregnancies originating from transfer of 2 IVF embryos had higher levels of PAG. Higher concentrations in the NT group during late pregnancy are probably the consequence of placental dystrophies; careful examination of the placenta showed the occurence of major placental hypertrophy $(n=2)$ associated with hydramnios $(n=2)$ and hydatiform molar ( $n=1$; peripartal bPAG value: 12350 ).

In conclusion, monitoring concentrations of bPAG during pregnancy following transfer of IVF or NT embryos may help to detect earlier placental abnormalities, embryonic mortality or abortion. 